\title{
RANCANG-BANGUN APLIKASI SISTEM DISKUSI PEMBELAJARAN ON-LINE PADA PERGURUAN TINGGI
}

\author{
Aris Martono ${ }^{1}$ \\ Padeli $^{2}$ \\ Rosalina Miliartha ${ }^{3}$ \\ Dosen Perguruan Tinggi Raharja ${ }^{1,}$ Dosen Perguruan Tinggi Raharja ${ }^{2}$, Alumni Perguruan \\ Tinggi Raharja ${ }^{3}$. \\ e-mail :aris.martono@raharja.info,padeli@raharja.info,Rosalinamiliartha@raharja.info
}

Diterima: 22 Januari 2015/Disetujui : 2 Februari 2015

\begin{abstract}
The development of information technology is growing rapidly as one of them used to interacting with other people. Information technology can connect us with others regardless of time and place. This is possible because of the existence of a container that community (forums) discussions on-line learning. However, in Higher Education of Raharja the development of discussion for learning is less developed for regular class or a class that is not a superclass or i-learning class because the manual is face to face or face to face for the discussion of learning in Higher Education of Raharja. Therefore, it can be made a formal community for container or the learning process in order to facilitate the discussion of faculty and students in the learning process outside of lecture hours that can be accessed anytime and anywhere and can provide accurate information so that the information obtained by the faculty and students to be more relevant. Discussion of web-based learning system is designed with a user friendly system so that is easy to access and understand, facilitate communication between faculty and students, and also facilitates getting materials lecture material, as well as assist in the distribution and collection of duties and tasks quickly lecturers also can manage the values that will given to students. The methodology used is a structured analysis and development ranging from analyzing the system that runs through UML, perform elicitation, and describes the proposed system through UML. The final results are achieved from this research is the creation of a learning system that can be accessed anywhere, anytime, and always follow the lecture material information or update.
\end{abstract}

Keywords :Discussion of web-based learning, face to face, user friendly

\begin{abstract}
ABSTRAK
Perkembangan teknologi informasi saat ini semakin pesat salah satunya digunakan untuk berinteraksi dengan orang lain. Teknologi informasi dapat menghubungkan kita dengan orang lain tanpa ada batasan waktu dan tempat. Hal ini dimungkinkan karena adanya suatu wadah yaitu komunitas (forum) diskusi pembelajaran on-line. Namun, di Perguruan Tinggi Raharja perkembangan diskusi pembelajaran ini kurang begitu berkembang untuk kelas reguler atau kelas yang bukan merupakan kelas unggulan atau kelas i-learning karena masih manual yaitu tatap muka atau face to face untuk proses diskusi pembelajaran di Perguruan Tinggi Raharja. Oleh karena itu, dapat dibuatkan sebuah wadah atau komunitas formal untuk proses diskusi pembelajaran agar memudahkan dosen dan mahasiswa dalam melakukan proses pembelajaran di luar jam perkuliahan sehingga dapat diakses kapan saja dan dimana saja dan dapat memberikan informasi yang akurat, sehingga informasi yang didapatkan oleh
\end{abstract}


dosen dan mahasiswa agar lebih relevan. Sistem diskusi pembelajaran berbasis web ini dirancang dengan sistem yang user friendly sehingga pengaksessanya mudah dipahami, mudah komunikasi antara dosen dan mahasiswa, dan juga mudah mendapatkan bahan materi perkuliahan, serta membantu dalam pendistribusian tugas dan pengumpulan tugas dan dosen pun dengan cepat bisa mengelola nilai yang akan diberikan kepada mahasiswa. Metodologi yang digunakan yaitu analisa dan pengembangan yang terstruktur mulai dari menganalisa sistem yang berjalan melalui UML, melakukan elisitasi, serta menggambarkan sistem yang diusulkan melalui UML. Hasil akhir yang dicapai dari penelitian ini yaitu terbentuknya suatu sistem pembelajaran yang dapat diakses dimana saja, kapan saja,dan selalu mengikuti informasi atau materi perkuliahan yang terupdate.

Kata Kunci : Diskusi pembelajaran, tatap muka, user friendly

\section{PENDAHULUAN}

Perkembangan teknologi informasi saat ini semakin pesat salah satunya digunakan untuk berinteraksi dengan orang lain. Teknologi informasi dapat menghubungkan kita dengan orang lain tanpa ada batasan waktu dan tempat. Hal ini dimungkinkan karena adanya suatu wadah yaitu komunitas (forum) diskusi pembelajaran online.

Setiap organisisasi seperti perguruan tinggi membutuhkan data dan informasi untuk berbagai kebutuhan.Ketersediaan data dan informasi yang cepat dan akurat serta didukung dengan penerapan sistem yang optimal menjadi kelebihan tersendiri yang harus dimiliki oleh setiap perguruan tinggi, hal tersebut dapat menjadi ukuran sejauh mana kualitas dari perguruan tinggi tersebut.

Pengertian on-line adalah untuk komputer yang berhubungan dengan komputer lain dalam bentuk jaringan, seadngkan pengertian offline adalah komputer yang bekerja sendiri dam tidak berhubungan dengan komputer lain. Dengan Internet kita dapat menerima dan mengakses informasi dalam berbagai format dari seluruh penjuru dunia.Kehadiran internet juga dapat memberikan kemudahan dalam dunia pendidikan, hal ini terlihat dengan begitu banyaknya situs web yang menyediakan media pembelajaran yang semakin interaktif serta mudah untuk dipelajari [1].
Dengan adanya diskusi pembelajaran on-line, user dapat memperoleh data dan informasi, dapat melakukan komunikasi antara mahasiswa dan dosen, saling berbagi pengetahuan, bisa melakukan diskusi, bertukar infomasi dan terutama bisa dilakukan kapan saja dan di mana saja tidak terbatas pada waktu dan tempat. Namun, di Perguruan Tinggi Raharja perkembangan diskusi pembelajaran ini kurang begitu berkembang untuk kelas reguler atau kelas yang bukan merupakan kelas unggulan atau kelas i-learning karena masih manual yaitu tatap muka atau face to face untuk proses diskusi. Akibat dari belum berkembangnya diskusi pembelajaran di Perguruan Tinggi Raharja, di antaranya yaitu sulit melakukan komunikasi atau diskusi pembelajaran di luar jam perkuliahan, sulitnya mengakses materi perkuliahan yang terupdate dari dosen, tidak adanya suatu wadah formal untuk saling berbagi pengetahuan, kurangnya waktu yang disediakan untuk proses pembelajaran ketika sedang ada di kelas terutama pada mata kuliah yang mempunyai bobot sebanyak 3 sks dan dikarenakan tidak seimbangnya jumlah mahasiswa dan dosen sehingga proses pembelajaran kurang maksimal.

Kurang seimbangnya jumlah dosen dan mahasiswa dapat dilihat dari data pernyebaran antara jumlah mahasiswa dan dosen yang dilihat dari tabel jumlah dosen dan mahasiswa dalam proses pembelajaran dibawah ini : 
Kualitas pendidikan secara umum, sangat dipengaruhi oleh aspek pendukung sistem pembelajaran, yaitu: sumber belajar, sumber daya manusia, infrastruktur dan sistem pembelajaran. Bahkan keempat aspek saling berinteraksi dalam mempengaruhi peningkatan sistem mutu pembelajaran.Sementara itu, sebagian besar penelitian telah dilakukan secara parsial pada aspek keempat adalah untuk meningkatkan kualitas pembelajaran.Salah satu topik yang telah diteliti adalah mengenai tentang sistem diskusi pembelajaran yang kurang begitu berkembang karena masih manual yaitu tatap muka atau face to face untuk kelas reguler pada Perguruan Tinggi Raharja. Melihat sistem-sistem yang digunakan pada Peguruan Tinggi Raharja sebagian besar sudah berjalan sudah on-lineakan tetapi pada sistem diskusi pembelajaran masih belum begitu berkembang untuk kelas reguler karena masih bersifat manual atau face to face ketika sedang melakukan perkuliahan di kelas.

Hal tersebut dinilai kurang maksimal karena kurangmya waktu untuk melakukan diskusi pembelajaran di kelas terutama pada mata kuliah yang mempunyai bobot sebanyak 3 sks. Selain itu pada Perguruan Tinggi Raharja dinilai masih mengalami kesulitan dalam melakukan komunikasi atau diskusi pembelajaran di luar jam perkuliahan lalu masih mengalami kesulitan dalam mengakses materi perkuliahan yang terupdate dari dosen karena hanya bisa diakses pada wilayah Perguruan Tinggi Raharja saja yaitu pada fasilitas Raharja Multimedia Edutainment (RME) dimana hanya dosen yang dapat mengakses RME untuk proses pembelajaran di kelas, dan yang terakhir belum adanya suatu wadah formal untuk saling berbagi pengetahuan. Sistem pembelajaran yang berjalan saat ini dapat dilihat pada gambar 1 di bawah ini.

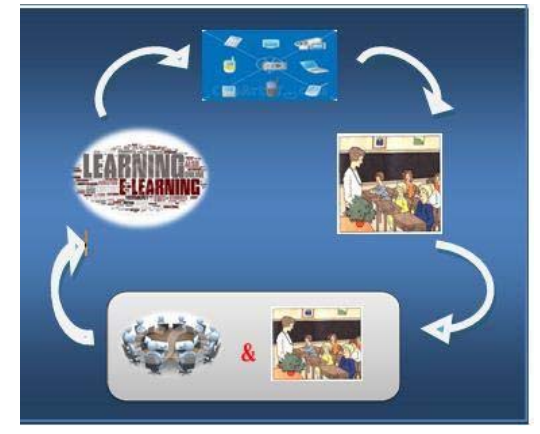

Gambar 1. Alur Diskusi Sistem Pembelajaran

\section{KAJIAN LITERATURE}

Dalam upaya mengembangkan dan menyempurnakan sistem pembelajaran ini perlu dilakukan kajian literatur sebagai salah satu dari penerapan metode penelitian ini sehingga diperoleh beberapa manfaat antara lain :

1. Mengidentifikasikan kesenjangan (identify gaps) dari penelitian ini.

2. Menghindari membuat ulang (reinventing the wheel) sehingga banyak menghemat waktu dan juga menghindari kesalahan-kesalahan yang pernah dilakukan oleh orang lain.

3. Mengidentifikasikan metode yang pernah dilakukan dan yang relevant terhadap penelitian ini.

4. Meneruskan apa yang penelitian sebelumnya telah dicapai sehingga dengan adanya kajian literatur ini dan penelitian yang akan dilakukan dapat membangun di atas platform dari pengetahuan atau ide yang sudah ada.

5. Untuk mengetahui orang lain yang spesialis dan mengerjakan di area penelitian yang sama, sehingga dapat terjaring dalam komunitas yang dapat 
memberi kontribusi sumber daya yang berharga.

Berikut adalah penelitian yang telah dilakukan dan memiliki korelasi yang searah dengan penelitian yang akan dibahas dalam laporan penelitian ini, antara lain :

1. Penelitian yang dilakukan oleh Hendra (2010) dari Perguruan Tinggi Raharja dalam bentuk Laporan Skripsi yang berjudul "Perancangan Sistem Pembelajaran Berbasis E-learning Pada SMK Bina Mandiri."Penelitian ini membahas tentang E-learning disajikan dalam bentuk Web. Sistem E-learning bisa dikatakan sebagai proses pembelajaran yang lebih mengutamakan ke-efektifan dan keefisienan baik dari segi waktu, biaya maupun materi pembelajaran yang ingin disampaikan. Konsep dan mekanisme yang ada pada E-learning ini adalah seluruh peserta pembelajaran baik itu pengajar maupun peserta didik akan terhubung dengan suatu sistem elektronik dimana semua peserta pembelajaran dapat berinteraksi dan berdiskusi, sehingga sistem pembelajaran dapat lebih efektif dan efisien dari sisi waktu dan biaya. Media E-learning memiliki manfaat yang lebih diantaranya yaitu peserta didik dapat berkomunikasi dengan pengajar dan sesama peserta didik tanpa dibatasi oleh ruang dan waktu, mengurangi biaya perjalanan, menghemat biaya pendidikan, dapat menjangkau wilayah geografis yang lebih luas dan dapat melatih pelajar agar lebih mandiri dalam mendapatkan ilmu pengetahuan.[2]

2. Penelitian yang dilakukan oleh Dini Alpiah (2010) dari Perguruan Tinggi Raharja dalam bentuk Laporan Skripsi dengan judul "Perancangan Sistem Informasi Raharja E-learning Campus Community dengan Metode Single Sign On pada Perguruan Tinggi Raharja”.
Penelitian ini membahas tentang $E$ learning disajikan dalam bentuk Web, adapun E-learning yang disajkan ini diperuntukkan bagi mahasiswa Perguruan Tinggi Raharja dan materi bahan ajar yang diperoleh adalah hasil input yang dilakukan oleh pihak dosen yang terkait dengan matakuliah yang di ampuh. Penelitian ini menghasilkan kolaborasi antara moodle dan teknologi dari Microsoft yaitu Live Edu.[3]

3. Penelitian yang dilakukan oleh Maimunah, Kristiana, Hendra (2009) dari Perguruan Tinggi Raharja dalam bentuk Laporan Jurnal CCIT vol.3 No.2-Januari 2010 dengan judul "Perancangan Aplikasi Forum Diskusi Pada Media E-learning Berbasis Web". Penelitian ini membahas tentang Forum Diskusi pada media E-learning disajikan dalam bentuk Web. Sistem E-learning dikatakan sebagai proses pembelajaran yang lebih mengutamakan keefisienan dan kefektifan baik dari segi waktu,biaya maupun materi pembelajaran yang ingin disampaikan. Kefektifan dan keefisinenan E-learning ini dapat dilihat pada salah satu aplikasi forum diskusi.[4]

4. Penelitian yang dilakukan oleh Prabowo Pudjo Widodo,Maimunah, Henderi (2010) dari Perguruan Tinggi Raharja dalam bentuk Laporan Jurnal CCIT vol2.No.3-Mei 2009 dengan judul “Kajian Persepsi Penggunaan Teknologi Pembelajaran Raharja Multimedia Edutainment(RME) Menggunakan Metode Technology Acceptance Model ". Penelitian ini membahas tentang teknologi pembelajaran Raharja Multimedia Edutainment(RME) yang digunakan untuk mendukung dan mempelancar pelaksaan kegiatan belajar mengajar, dan memenuhi kebutuhan informasi yang berhubungan denganya.Penilitian ini bertujuan 
untuk mengetahui faktor-faktor yang mempengaruhi diterima dengan baik atau tidaknya RME oleh penggunanya. Juga ini diketahui hubungan anatra faktor-faktor yang mepengarhi penerimaan RME. Model yang digunakan untuk mengetahui penerimaan RME pada penelitian ini adalah model TAM ( Acceptance Model). Model TAM secara rinci menjelaskan penerimaan teknologi inforimasi (TI) dengan dimensidimensi tertentu yang dapat mempengaruhi penerimaan teknologi oleh pengguna. [5]

5. Penelitian yang dilakukan oleh Danny Wiliam Wongso (2008) dari Universitas Bina Nusantara sebagai bentuk Skripsi dengan judul “Analisa dan Perancangan Piranti Lunak Pembangkit Soal Ujian Secara Online dengan menerpakan AJAX”. Pada tugas akhir ini penulis bertujuan mengidentifikasi kebutuhan Universitas Bina Nusantara yang berkaitan dengan persedian soal ujian, menganalisis dan merancang database, serta membuat aplikasi pembangkit soal ujian. Manfaatnya adalah untuk mendukung kemudahan proses penyediaan soal ujian sesyau Satuan Acara Perkuliahan (SAP). Penelitian ini menggunakan metode analisis dengan studi kepustakaan ( sumber tertulis maupun online) dan metode perancangan dengan analisis terhadap sistem yang berjalan untuk medeyeksi masalah yang ada. Pendekatan dalam menganalisis dan merancang sistem pembangkit soal ujian adalah dengan pendekatan Object-Oriented Analysis dan Design (OOAD) dengan penggambaran notasi Unified Modelinh Language (UML). Notasi UML menjelaskan garis besar serta rincian dari sistem pembangkit soal ujian. Relational database menjelaskan struktur data yang digunakan dalam sistem. Dalam notasi UML, atribut obyek yang terliabat mendukung struktur tabel; yang ada, dalam bentuk atribut data. Integrasi dari kedua perancangan tersebut adalah bentuk model perancangan layar. Aplikasi pembangkit soal ujian secara online yang menerapkan AJAX merupakan hasil penelitian. Aplikasi ini meningkatkan efektifitas proses pembangkit soal ujian, dalam hal mempermudah proses penyimpanan soal ujian, membuat variasi soal, dan menn-generate soal ujian sesuai dengan kriteria soal ujian yang telah ditetapkan. [6]

6. Penelitian yang dilakukan oleh Herman Dwi Surjono dari College of Engineering, Yogyakarta State University yang berjudul “ The Development of An Adaptive $E$ learning Toward The Learning Style Diversity of Visual-AuditoryKinesthetic". Hasil penelitian ini menghasilkan adaptive e-learning, dimana adaptive e-learning adalah sistem e-learning yang mampu mengadaptasi tampilan materi pembelajarannya sesuai dengan karakteristik peserta didik. Melalui $e$ learning ini diharapkan para peserta didik dapat belajar secara optimal karena mereka mendapatkan materi pembelajaran sesuai dengan yang dibutuhkan. Materi yang disajikan dalam e-learning ini tergantung dari kecenderungan gaya belajar peserta didik. Setelah peserta didik login dan memilih mata pelajaran, mereka akan mengisi kuisioner sehingga sistem akan mengidentifikasi bagaimana kecenderungan mereka, kecenderungan gaya belajar dikategorikan menjadi tiga yaitu Visual, Auditory dan Kinestetik.[7]

7. Penelitian yang dilakukan oleh Priyanto dari Fakultas Teknik dari Universitas Negeri Yogyakarta dengan judul "Model E-learning Readiness sebagai strategi pengembangan E-learning”. Penelitian ini membahas tentang $e$ - 
learning Readiness dimana Readiness didefinisikan sebagai kesiapan mental atau fisik suatu organisasi untuk suatu pengalaman pembelajaran. Model ELR (e-learning Readiness) ini berguna untuk menyederhanakan proses dalam memperoleh informasi dasar yang diperlukan dalam mengembangkan e-learning.[8]

8. Penelitian yang dilakukan oleh Sukriya dari ITS (Institut Teknologi Sepuluh Nopember) [2009] sebagai bentuk skripsi dengan judul "Perancangan dan Pembuatan Perangkat Lunak E-learning Berbasis .Net Menggunakan Teknologi ASP.Net 3.5 dan Ajax dengan Partial Rendering untuk Studi Kasus Scored Online Test “. Hasil laporan ini adalah eksplorasi teknologi baru Ajax ASP.Net serta pemanfaatannya dengan menggunakan studi kasus pembuatan perangkat lunak e-learning dengan scored online test. E-learning membawa pengaruh terjadinya proses transformasi pendidikan konvensional ke dalam bentuk digital, baik secara isi dan sistemnya. Begitu juga untuk mendapatkan feed back evaluasi pembelajaran secara cepat, tes online menjadi suatu alternative untuk mendapatkan hasil yang optimal dengan pelaksanaan tes yang dapat dilakukan tanpa terhalang waktu dan tempat. Aplikasi yang mendukung hal ini biasanya berbasis web yang interaktif dan dinamik. Ajax ASP.Net 3.5 merupakan salah satu framework Ajax untuk ASP.Net 3.5. Tugas akhir ini diharapkan dapat diaplikasikan dan dapat memberikan kontribusi bagi perkembangan e-learning ke depan.[9]

Hasil kajian literatur ini mendemonstrasikan landasan (platform) yang kokoh serta alasan yang kuat untuk mengembangkan Sistem diskusi Pembelajaran On-line menjadi lebih baik lagi dengan pertimbangan yang sudah matang. Kesenjangan (gaps) telah teridentifikasi dengan baik sehingga tidak terjadi pembuatan ulang (reinventing the wheel). Peninjauan telah dilakukan dengan matang, sehingga dipastikan akan menghasilkan project yang maksimal, dan membuat kegiatan belajar mengajar menjadi lebih efektif dan memudahkan manajemen dalam menerima informasi untuk mengambil suatu kebijakan atau keputusan, serta Mahasiswa (stakeholder) merasa termotivasi dan terlayani dengan baik (service excellence).

\section{METODOLOGI PENELITIAN}

Untuk menerapkan pada Sistem Diskusi Pembelajaran On-line dalam penyebaran informasi dimana studi kasus di Perguruan Tinggi Raharja, menggunakan beberapa metode yaitu pengumpulan data, tehknik memperoleh sumber data, metode analisa sistem, dan metode dalam perancangan sistem.

Metode pengumpulan data dengan melakukan wawancara yaitu melakukan sesi tanya jawab kepada narasumber yaitu para stakeholder--staff dan dosen--di lingkungan Perguruan Tinggi Raharja. Metode kedua adalah metode observasi yaitu melakukan pengamatan langsung di tempat aktivitas kerja berlangsung dan peneliti melakukan pencatatan secara sistematik terhadap unsur-unsur yang diteliti.Metode ketiga adalah metode studi pustaka yaitu melakukan penelitian ke perpustakaan dengan tujuan agar memperoleh data teoritis yang bersumber dari buku - buku ilmiah mengenai sistem pendataan tersebut.

Teknik memperoleh data primer dan sekunder.Teknik memperoleh data primer yaitu teknik memeperoleh data secara langsung dari Perguruan Tinggi, baik melalui observasi maupun melalui pengumpulan data. Teknik memperoleh data sekunder adalah teknik pengumpulan data dengan mempelajari buku-buku, dan sumber-sumber data lainnya yang 
berkaitan dengan objek penelitian yang dipilih.

Metode analisa sistem. Setelah proses pengumpulan data dilaksanakan melalui beberapa teknik, maka data yang sudah ada akan diolah dan dianalisis agar mendapatkan suatu hasil akhir yang bermanfaat bagi penelitian ini. Dalam metode analisis sistem dilakukan melalui 4 tahap, yaitu :

1. Survey terhadap sistem yang berjalan,

2. Analisis terhadap sistem yang berjalan,

3. Identifikasi kebutuhan informasi,

4. Identifikasi persyaratan system.

Metode Perancangan Sistem. Dalam metode perancangam sistem ini menggunakan tool UML (Unified Modeling Language) yaitu visual paradigm 6.4 Enterprise Edition, dan melakukan implementasi dengan membuat prototype dan dibantu dengan control panel Macromedia Dreamwaver CS5 dengan fasilitas PHP , CSS dan database MySQL.

\section{HASIL DAN PEMBAHASAN}

\section{A. Pemecahan Masalah}

Setelah mengamati dan meneliti dari beberapa permasalahan yang terjadi pada sistem yang berjalan, terdapat beberapa alternatif pemecahan dari permasalahan yang dihadapi, antara lain :

1. Dapat dibuatkan sebuah wadah atau komunitas formal untuk proses diskusi pembelajaran agar memudahkan dosen dan mahasiswa dalam melakukan proses pembelajaran di luar jam perkuliahan sehingga dapat diakses kapan saja dan dimana saja.

2. Dapat memberikan informasi yang akurat, sehingga informasi yang didapatkan oleh dosen dan mahasiswa lebih relevan. Selain itu, informasi didapatkan secara cepat, tepat dan akurat sesuai dengan kebutuhan .

Pemecahan masalah ini dapat digambarkan pada gambar 2 activity diagram mahasiswa di bawah ini.

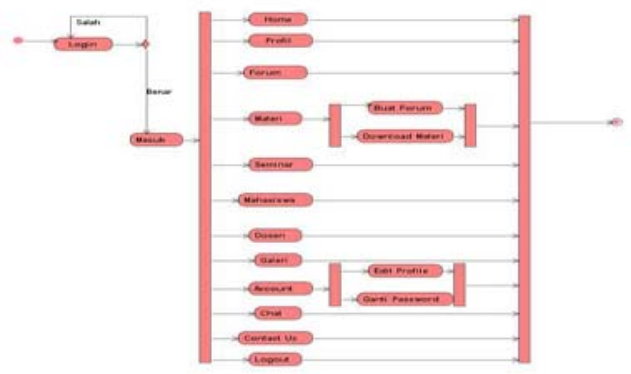

Gambar 2 Activity Diagram Mahasiswa

\section{B. Rancangan Basis Data}

Pada perancangan database diskusi pembelajaran ini, dibuat tabel-tabel yang saling berhubungan untuk dijadikan gambaran bagaimana sistem diskusi pembelajaran tersebut. Pada gambar 3 class diagram diskusi pembelajaran ini dapat dilihat pada gambar di bawah ini.

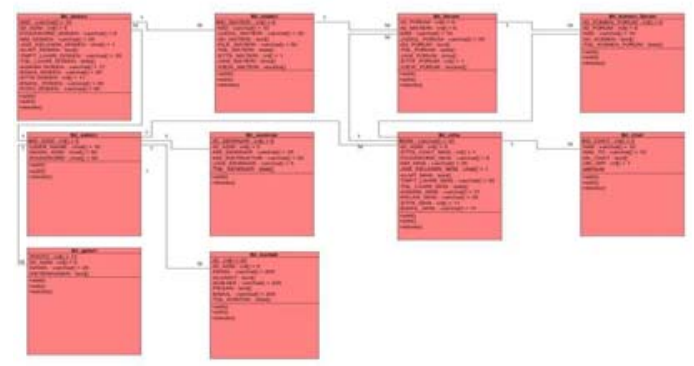

Gambar 3 Class Diagram Diskusi Pembelajaran

Berdasarkan Gambar 4.10 Class Diagram yang diusulkan terdapat :

a. 10 class, himpunan dari objek-objek yang berbagi atribut serta operasi yang sama.

b. 11 association, digunakan untuk memodelkan relasi di antara objek.

\section{Implementasi}

Peningkatan kinerja sistem diskusi pembelajaranon-line untuk kelas reguler sudah diimplementasikan pada Perguruan Tinggi Raharja yakni pada media informasi yang dapat diakses langsung oleh Perguruan Tinggi Raharja yaitu Dosen, Mahasiswa dan Admin demi menunjang sistem yang berjalan. 
Hasil akhir yang ingin dicapai dari sistem diskusi pembelajaran on-line yaitu dengan adanya wadah atau komunitas formal (forum) yang dapat diakses langsung oleh Perguruan Tinggi Raharja dapat mendukung sistem diskusi pembelajaran saat ini karena sistem diskusi pembelajaran sebelumnya dinilai kurang efektif dimana diskusi pembelajaran masih bersifat tatap muka atau face to face.

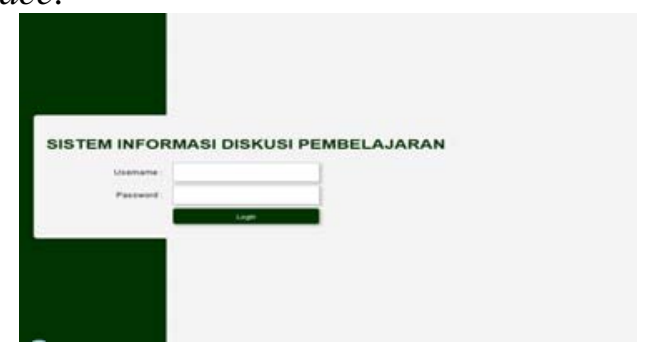

Gambar 4 Tampilan Halaman Login Mahasiswa,Dosen dan Admin

Tampilan ini merupakan tampilan login untuk masuk kedalam sistem diskusi pemebelajaran dapat dilihat pada gambar 4 di atas.Untuk dapat login user harus memasukkan password sesuai dengan username masing-masing user.

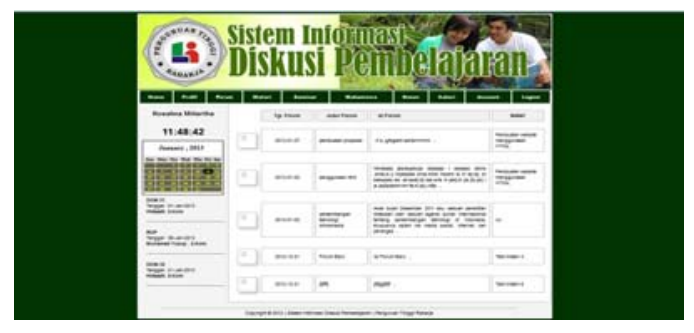

Gambar 5 Tampilan Mahasiswa,dosen dan admin Halaman Utama

Gambar 5 diatas merupakan tampilan halaman utama. Setelah melakukan Login dan dinyatakan berhak memasuki ke dalam sistem diskusi pembelajaran akan muncul tampilan halaman utama. Pada sisi kanan akan muncul nama dari user yang melakukan login dan juga di bawahnya terdapat waktu dan tanggal ketika user mengakses sistem diskusi pembelajaran.

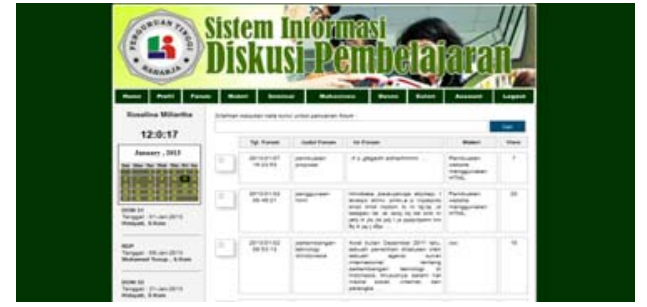

\section{Gambar 6 Tampilan Halaman Forum}

Gambar 6 diatas ini merupakan tampilan halaman forum.Dimana mahasiswa yang telah login dapat membuat forum dari materi yang telah dibuat oleh dosen.Dan hanya mahasiswa yang dapat memiliki akses buat forum.

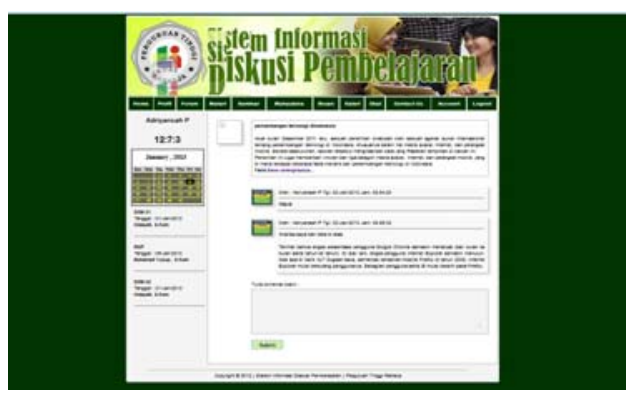

Gambar 7 Tampilan Halaman Komen Forum

Gambar 7 di atas ini merupakan tampilan halaman komentar forum.Dimana user dapat mengkomentari forum sesuai dengan materi forum yang dipilih.Dari halaman forum ini kita dapat melakukan diskusi pembelajaran dan menambah pengetahuan dari informasi-informasi yang didapat daru forum tersebut.

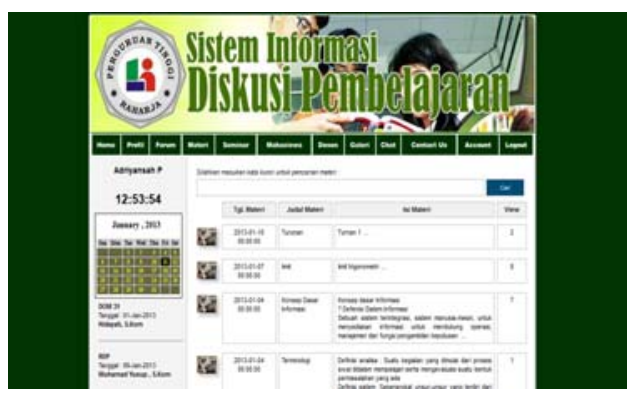


Gambar 8 Tampilan Halaman Materi

Gambar 8 di atas ini merupakan tampilan halaman materi. Dimana ketika dosen melakukan login dosen dapat membuat dan mengupload materi serta dapat melakukan delete dan edit materi sedangkan ketika mahasiswa melakukan login mahasiswa dapat melakukan download materi, dan buat forum sesuai dengan materi yang dibuat oleh dosen. Dan yang ketika admin yang melakukan login maka admin hanya dapat melakukan download materi.

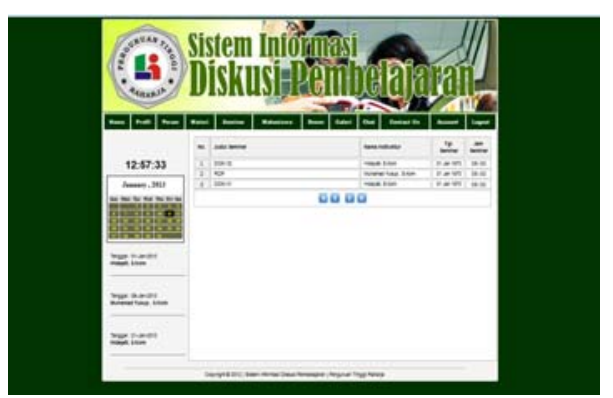

\section{Gambar 9 Tampilan Halaman Seminar}

Gambar 9 di atas merupakan tampilan halaman seminar.Dimana mahasiswa dapat mengetahui informasi seminar yang terupdate. Hanya admin yang memiliki akses untuk menambah dan delete informasi seminar.

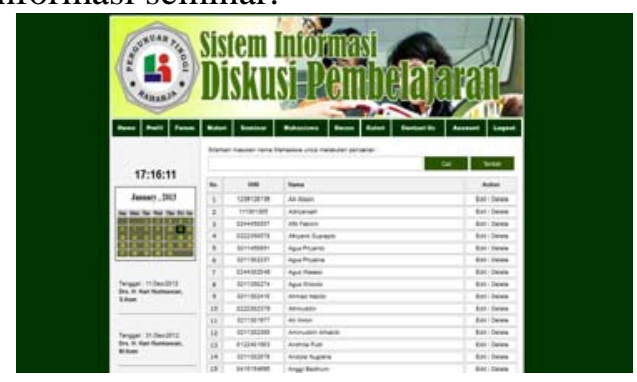

\section{Gambar 10 Tampilan Halaman Mahasiswa}

Gambar 10 diatas merupakan tampilan halaman mahasiswa.Dimana user dapat mengetahui jumlah dan profil dari mahasiswa yang aktif. Hanya admin yang memiliki akses untuk tambah, edit, delete mahasiswa.

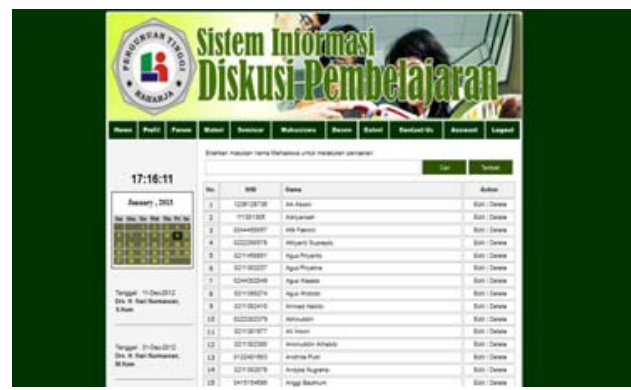

Gambar 11 Tampilan Halaman Dosen

Gambar 11 di atas merupakan tampilan halaman dosen.Dimana user dapat mengetahui jumlah dan profil dari dosen yang aktif. Hanya admin yang memiliki akses untuk tambah, edit, delete dosen.

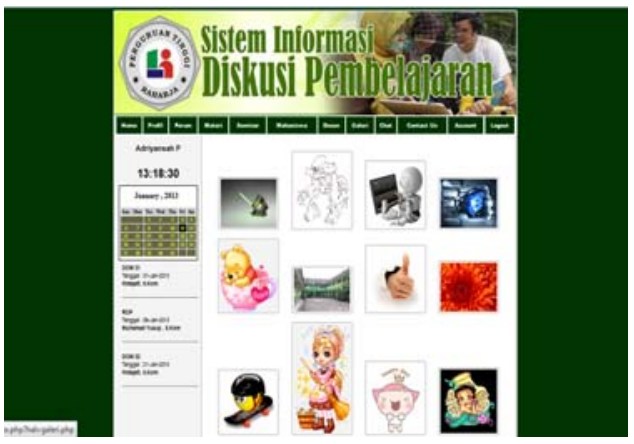

Gambar 12 Tampilan Halaman Galeri

Gambar 12 di atas merupakan tampilan halaman galeri.Dimana user dapat melihat foto dari kegiatan pembelajaran kampus.

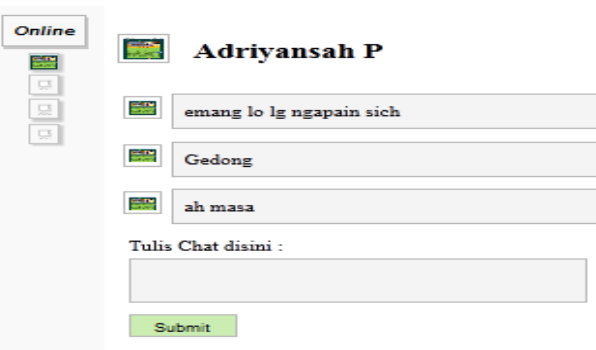

Gambar 13 Tampilan Halaman Chatting 
Gambar 13 di atas merupakan tampilan halaman chatting. Dimana user dapat berkomunikasi secara personal antar user lain melalui chatting. Pada sisi kiri akan muncul daftar user yang sedang online.

\section{Listing Program}

$<$ ?

\$cek=date('Ymd');

?>

$<$ ? if $(\operatorname{trim}(\$ c e k<20130601))$ \{

?>

<body bgcolor="\#003300" topmargin="0" bottommargin="0" rightmargin="0" leftmargin="0">

<table width="100\%" height="100\%" border="0" cellpadding="0" cellspacing="0">

$<\operatorname{tr}>$

$<$ td width="200" >\&nbsp; </td >

$<$ td bgcolor="\#f4f4f4">\&nbsp; </td >

$</ \operatorname{tr}>$

$<\operatorname{tr}>$

$<$ td height="100" colspan="2" align="left" valign="middle" style="paddingleft:20px" > >table width="100\%" border="0" cellspacing="2" cellpadding="2" $\quad$ bgcolor="\#f4f4f4" style="font-family:Arial, Helvetica, sansserif; font-size:12px; color:\#000; borderradius: $5 \mathrm{px}$;

-moz-border-radius:8px; -webkitborder-radius:8px; vertical-align:middle; box-shadow:3px 3px 3px rgba(0,0,0,0.20);">

$<$ form name="form" id="form" class="form" action="conf/login_post.php"

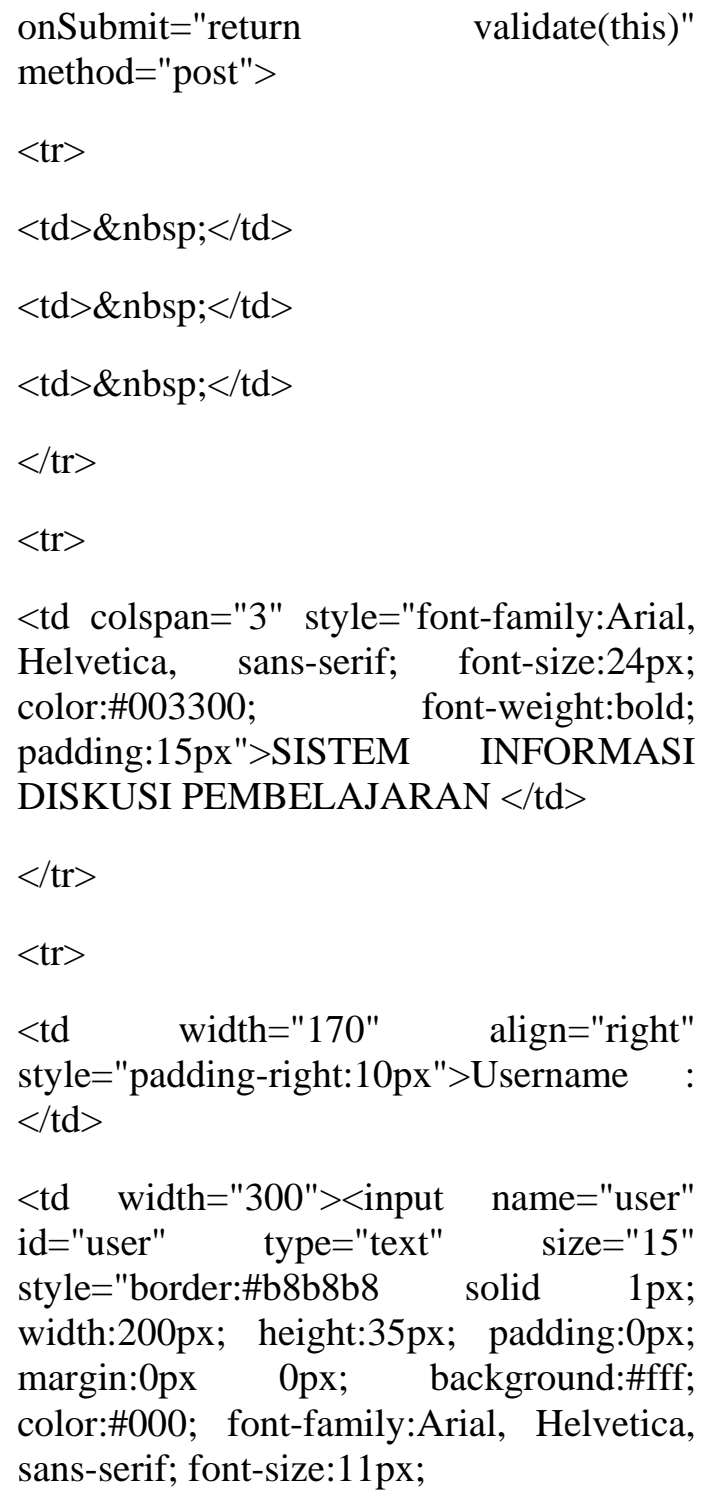
sans-serif; font-size:11px;

-moz-border-radius:3px; -webkitborder-radius:3px; vertical-align:middle; box-shadow:3px 3px 3px rgba(0,0,0,0.20)" $1></ \mathrm{td}>$

$<\mathrm{td}>$ \&nbsp; $</ \mathrm{td}>$

$</ \operatorname{tr}>$

$<\operatorname{tr}>$

$<$ td $\quad$ width="170" align="right" style="padding-right:10px">Password : $</$ td $>$

$<$ td width="300" $><$ input name="pass" id="pass" type $=$ "password" size $=$ "15" style="border:\#b8b8b8 solid 1px; 
width:200px; height:35px; padding:0px; margin:0px 0px; background:\#fff; color:\#000; font-family:Arial, Helvetica, sans-serif; font-size:11px;

-moz-border-radius:3px; -webkitborder-radius:3px; vertical-align:middle; box-shadow:3px 3px 3px $\operatorname{rgba}(0,0,0,0.20) " /></$ td $>$

$<\mathrm{td}>$ \&nbsp; $</ \mathrm{td}>$

$</ \operatorname{tr}>$

$<\operatorname{tr}>$

$<\mathrm{td}>$ \&nbsp; $</ \mathrm{td}>$

$<$ td $><$ input name="button" type="submit" class="post" id="button" value="Login" style="border:\#b8b8b8 solid 0.5px; width:200px; height:30px; padding:0px; margin:0px 0px; background:\#003300; color:\#fff; font-family:Arial, Helvetica, sans-serif; font-size:11px; border-radius: 5px;

-moz-border-radius:8px; -webkitborder-radius:8px; vertical-align:middle; box-shadow:3px 3px 3px rgba(0,0,0,0.20); cursor:pointer" $/></$ td $>$

$<$ td $>$ \&nbsp; $</$ td $>$

$</ \operatorname{tr}>$

$<\operatorname{tr}>$

$<$ td width="170" $>$ \&nbsp; $</$ td $>$

$<$ td width="300" > \&nbsp; </td >

$<\mathrm{td}>$ \&nbsp; $</ \mathrm{td}>$

$</ \operatorname{tr}>$

$</$ form $>$

$</$ table $></$ td $>$

$</ \operatorname{tr}>$

$<\operatorname{tr}>$

$<$ td width="200" >\&nbsp; </td $>$

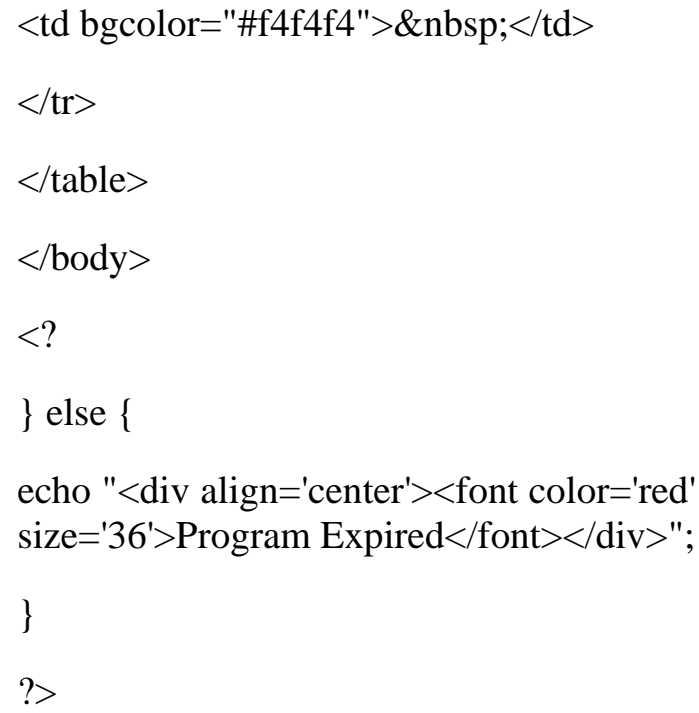

\section{KESIMPULAN}

Sistem yang berjalan saat ini di Perguruan Tinggi Raharja masih belum begitu berkembang karena masih bersifat tatap muka atau face to face sehingga informasi yang didapatkan kurang maksimal, karena hanya mengandalkan pertemuan di kelas.

Pada sistem yang baru diharapkan lebih efektif dan efisien dimana sistem pembelajaran dapat diakses dimana saja, kapan saja,dan selalu mengikuti informasi atau materi perkuliahan yang terupdate sehingga dapat memaksimalkan kegiatan pembelajaran yang ada di Perguruan Tnggi Raharja. Program baru ini diharapkan informasi dapat berjalan dengan baik dan juga sebagai bentuk peningkatan kualitas informasi pada Perguruan Tinggi Raharja.

\section{DAFTAR PUSTAKA}

[1]Henderi, Maimunah, Randy Andrian. Desain Aplikasi E-Learning Sebagai Media Pembelajaran Artificial Informatics CCIT Journal Vol 4 No.3-Mei 2011.Tangerang. Perguruan Tinggi Raharja. 2011.

[2]Hendra.Perancangan Sistem Pembelajaran Berbasis eLearning.Skripsi.Tangerang.Rah arja.2010. 
[3]Dini Alpiah. Perancangan Sistem Informasi Raharja e-Learning Campus Community dengan Metode Sign

On.Skripsi.Tangerang.2010.

[4]Maimunah, Kristiana, Hendra. Perancangan Aplikasi Forum Diskusi Pada Media e-Learning berbasis web.CCIT Journal Vol.3 No.2. Perguruan Tinggi Raharja. Tangerang. 2009.

[5]Prabowo,Maimunah, Henderi. Kajian Persepsi Penggunaan Teknologi Pembelajaran Acceptance Model.CCIT Journal vol.2 N0.3.Perguruan Tinggi Raharja.Tangerang.2009.

[6]Danny Wiliam. Analisa dan Perancangan Piranti Lunak Pembangkit Soal Ujian Secara Online dengan menerpakan AJAX.Skripsi. Jakarta. Bina Nusantara.2008.

[7]] Herman Dwi. The Development of An Adaptive E-learning Toward The Learning Style Diversity of Visual-Auditory-

Kinesthetic.Yogyakarta. College of Engineering

[8]Priyanto. Model E-learning Readiness sebagai strategi pengembangan E-learning. Yogyakarta.

[9]Sukriya. Perancangan dan Pembuatan Perangkat Lunak E-learning Berbasis .Net Menggunakan Teknologi ASP.Net 3.5 dan Ajax dengan Partial Rendering untuk Studi Kasus Scored Online Test. Skripsi.Surabaya.Institut

Teknologi Sepuluh November.2009. 